\title{
Zur Bestimmung kleiner Mengen Methylalkohol, Formaldehyd
} und Ameisensäure lässt sich nach $\mathrm{Nicloux}{ }^{1}$ ) das von ihm schon früher ausgearbeitete Verfahren zur Bestimmung kleiner Alkoholmengen ${ }^{2}$ ) verwenden, welches, auf der Oxydation des Alkohols durch Kaliumbichromat und Schwefelsäure beruht. Diese Körper müssen jedoch, und das ist der Nachteil des Verfahrens, allein als solche in den zu untersuchenden Lösungen sein, da ja auch andere organische Substanzen von dem Oxydationsgemisch angegriffen werden. Die Bestimmung selbst jedoch ist von einer Genauigkeit, wie sie von keiner andern Methode erreicht wird.

Die Ausführung ist dieselbe, wie sie schon bei der Alkoholbestimmung angegeben ist. $\mathrm{Zu}$ jedem Versuch wendet man $5 c c$ konzentrierte Schwefelsäure an auf $5 c c$ der zu prüfenden Lösung. Man erhitzt 1 Minute und wartet, ehe man abliest, 5 Minuten.

Die Stärke der Kaliumbichromatlösung ist für die einzelnen Verbindungen verschieden, und enthält wenig mehr, als sich nach folgenden Gleichungen berechnet:

$\mathrm{CH}_{3} \mathrm{OH}+\mathrm{K}_{2} \mathrm{Cr}_{2} \mathrm{O}_{7}+4 \mathrm{H}_{2} \mathrm{SO}_{4}=\mathrm{Cr}_{2}\left(\mathrm{SO}_{4}\right)_{3}+\mathrm{K}_{2} \mathrm{SO}_{4}+\mathrm{CO}_{2}+6 \mathrm{H}_{2} \mathrm{O}$ $3 \mathrm{HCOH}+2 \mathrm{~K}_{2} \mathrm{Cr}_{2} \mathrm{O}_{7}+8 \mathrm{H}_{2} \mathrm{SO}_{4}=2 \mathrm{Cr}_{2}\left(\mathrm{SO}_{4}\right)_{3}+2 \mathrm{~K}_{2} \mathrm{SO}_{4}+3 \mathrm{CO}_{2}+11 \mathrm{H}_{2} \mathrm{O}$ $3 \mathrm{HCOOH}+\mathrm{K}_{2} \mathrm{Cr}_{2} \mathrm{O}_{7}+4 \mathrm{H}_{2} \mathrm{SO}_{4}=\mathrm{Cr}_{2}\left(\mathrm{SO}_{4}\right)_{3}+\mathrm{K}_{2} \mathrm{SO}_{4}+\mathrm{CO}_{2}+7 \mathrm{H}_{2} \mathrm{O}$.

Zur Bestimmung von Methylalkohol löst man $19 \mathrm{~g}$ Kaliumbichromat im Liter; $2 c c$ dieser Lösung entsprechen $5 c c$ einer Lösung von $1 c c$ Alkohol im Liter.

Bei Formaldehyd verwendet man eine Bichromatlösung von $17 \mathrm{~g}$ pro Liter; $2 c c$ dieser Lösung entsprechen $5 c c$ einer Lösung, welche $1 \mathrm{~g}$ Formaldehyd im Liter enthält.

Die Ameisensäure bestimmt man mit einer Lösung von $11 g \mathrm{~K}_{2} \mathrm{Cr}_{2} \mathrm{O}_{7}$ im Liter. Es entspricht dann ebenfalls $1 c c$ dieser Lösung $5 c c$ einer 0,1 prozentigen Ameisensäurelösung.

Der Verfasser empfiehlt noch die Anwendung einer Reihe Vergleichsröhrchen mit titrierten Lösungen, um schon aus der Farbe der gelblichgrünen Lösung auf den Gehalt schliessen zu können.

Eine Methode zur quantitativen Trennung der Isovalerian- und Essigsäure gibt A Ifred C. Chapman ${ }^{3}$ ) an.

1) Bull. de la soc. chim. de Paris (3. Série) 27, 839.

2) Diese Zeitschrift 38, 257.

3) The Analyst 24, 114. 
Zur Bestimmung der beiden Säuren neben einander sind zwar bereits mehrere Wege vorgeschlagen, doch haben sie sich zur Trennung derselben nicht geeignet erwiesen. So erhält man zum Beispiel durch Titration des Säuregemisches mit Barytlauge und, nachherige Bestimmung des Baryumgehaltes der Salze nur annähernde Werte, da man die Barytsalze nicht leicht in reinem und trockenem Zustand herstellen kann. Ausserdem leidet die Methode wie alle indirekten Methoden an dem Übelstand, dass sich kleine Versuchsfehler stark multiplizieren.

Das von Chapman ausgearbeitete Verfahren beruht auf dem verschiedenen Verhalten der Natronsalze der beiden Säuren zu einem Gemisch von $99,5 \%$ Azeton und $0,5 \%$ Wasser. Während das isovaleriansaure Natron hierin in der Hitze leicht löslich ist, wird das Natriumazetat nicht angegriffen. Eine Reihe genauer Versuche zeigt die Richtigkeit dieser Tatsache. Man hat also zur Trennung auf folgende Weise zu verfahren:

Die Säuren werden mit reiner Natronlauge genau neutralisiert und unter Luftverdünnung zur Trockene verdampft. Der Rückstand wird in einem Luftbade kurze Zeit bei $100^{\circ}$ getrocknet und dann mit dem Azetongemisch extrahiert. Man filtriert rasch durch einen Trichter, welcher etwas Glaswolle und darüber eine dünne Lage feinen Asbest enthält, wäscht zweimal mit Azeton nach, destilliert im Filtrat das Azeton $a b$ und dampft zur Trockene.

Das auf dem Filter und im Extraktionskölbchen zurückgebliebene Natriumazetat löst man in Wasser und dampft es ebenfalls in einer Schale zur Trockene. Die beiden Salze werden alsdann durch Behandeln mit Schwefelsäure in Sulfate übergeführt and aus diesen die Mengen der Säuren berechnet.

Die angeführten Beleganalysen zeigen sehr gut. übereinstimmende Resultate.

Meist fällt die Bestimmung der Valeriansäure etwas zu niedrig, die der Essigsäure eine Kleinigkeit zu hoch aus, was darauf beruht, dass das Natriumazetat sich nicht vollständig auswaschen lässt.

Die Kalisalze können zur Trennung nicht verwendet werden, da das Kaliumisovalerianat dem Lösungsmittel Wasser entzieht und das Azetat eine Paste bildet. 